\title{
Sobre la relación de Garcilaso con Antonio Tilesio y el círculo de los hermanos Seripando
}

Recibido: 01/05/2012

Revisado: 04/07/2012

Aceptado: 15/07/2012

\author{
Eugenia FOSALBA VELA \\ Universitat de Girona \\ eugeniafosalba@gmail.com
}

\section{RESUMEN}

En este artículo se trata de demostrar la inmediata adaptación de Garcilaso a su llegada a Nápoles en 1532, a través del análisis del contenido de la Oda a Tilesio, una de cuyas copias se conserva entre los papeles privados de los hermanos Seripando (Ms. XIII AA 63 de la Biblioteca Nacional de Nápoles). Dicha documentación, además, apenas estudiada ni editada, permite trazar un panorama muy revelador de las relaciones de Garcilaso con otros humanistas y poetas en la ciudad partenopea.

Palabras clave: Garcilaso, Antonio Tilesio, Hermanos Seripando, Mario Galeota, Placido di Sangro, Cosimo Anisio, Giano Anisio, Scipione Capece.

\section{On Garcilaso's relationship with Antonio Tilesio and the circle of the Seripando Brothers}

\begin{abstract}
This article deals with the stay of Garcilaso in Naples and tries to show that he easily adapted to the city immediately after his arrival there in 1632, taking into account the content of the Ode to Tilesio, a copy of which is to be found amongst the private papers of the Seripando brothers (Ms. XIII AA 63, of the Biblioteca Nazionale, Naples). That documentation, which has scarcely been studied or published, also makes it possible to draw a very revealing picture of Garcilaso's relationship with other Neapolitan humanists and poets.
\end{abstract}

Keywords: Garcilaso, Antonio Tilesio, Seripando Brothers, Mario Gaelota, Placido di Sangro, Cosimo Anisio, Giano Anisio, Scipione Capece.

Los papeles de Antonio y Girolamo Seripando que custodia la Biblioteca Nacional de Nápoles recogen no solo gran parte de la correspondencia de ambos, sino un conjunto muy interesante de composiciones poéticas de variada autoría y factura, la 
mayoría de ellas escrita en latín, otras en griego, y otras cuantas en italiano ${ }^{2}$. Este material ha sido solo parcialmente estudiado y editado, y quedan por realizar las ediciones de la mayoría de los textos, así como el estudio de su contexto, e incluso la resolución de la cuestión de su autoría en algunos casos ${ }^{3}$. Dos copias de las composiciones neolatinas de Garcilaso de la Vega (Sedes ad Cyprias Venus y Uxore, natius, fratribus, et solo, dedicada esta última a Antonio Tilesio) se conservan precisamente entre esa documentación privada, además de su última carta, autógrafa, dirigida a Girolamo Seripando, a quien nuestro poeta escribió desde Savigliano pocas semanas antes de morir. Sorprendentemente, el hecho de que esos textos de Garcilaso se conserven entre la documentación privada de los hermanos Seripando no se ha considerado nunca como un dato revelador de la pertenencia de nuestro poeta al mismo círculo de poetas y humanistas postpontanianos cuyas cartas y obras quedan consignadas ahí por amistad. La intención es ofrecer en este artículo algunas pinceladas de ese contexto, poco estudiado, que acogió al Garcilaso neolatino, a la espera de editar algunos de los textos más adelante ${ }^{4}$.

Como preámbulo, revisaremos algunos aspectos de la formación del toledano en España, que lo convirtieron en un poeta a la altura de los más innovadores vates napolitanos, antes de instalarse en Nápoles en 1532. Recordar a vuelapluma aquí sus relaciones en Toledo con humanistas italianos de primer orden nos pondrá sobre la pista de la calidad de su formación, previa a la fecha axial de 1532, lo que a su vez explicará su inmediata integración en Nápoles en el último tramo de su vida, integración instantánea de la que también aquí ofreceremos pruebas significativas. Todo ello pone en cuestión el tópico que puso de moda el fundamental estudio de Rafael Lapesa, hace ya sesenta años, acerca de la trayectoria poética de Garcilaso, que ha vertebrado los estudios del poeta desde entonces, guiando con diáfana pedagogía la lectura del príncipe de los poetas castellanos de varias generaciones, no sin crear, sin embargo, puntos ciegos en cuestiones capitales: habría que revisar, entre otras cosas, el acento que siempre se pone en los cambios radicales que supuestamente esa última estancia en Italia pudo conllevar, lo que incluso ha servido para dar fecha a sus poemas. Tras poner en cuarentena ese cliché, trataremos de ofrecer detalles inéditos sobre el contexto napolitano, el entorno de los hermanos Seripando, en que vivió el poeta, gracias sobre todo a la información que nos ofrece la Oda a Tilesio, conservada en copia, como ya hemos señalado, entre esa documentación. Nos referiremos, además, a algunos detalles de las jerarquías del virreinato de la corona aragonesa y de la relación de esas estructuras de poder con poetas y humanistas, indagación que de forma lateral descubre aspectos de la realidad a la que

${ }^{2}$ Especialmente el Ms. XIII AA 63. El presente artículo se ha escrito en el marco del proyecto Diego Saavedra Fajardo y las corrientes intelectuales y literarias del humanismo (FFI2008-01417).

${ }^{3}$ Véanse las trascripciones de algunas de dichas obras en Altamura (1941), Fuiano (1969) y Gallo (Gaurico ed. 1998).

${ }^{4}$ Este estudio es un avance de las investigaciones que la autora está realizando acerca de estos manuscritos, dos de cuyas églogas latinas, hasta el momento inéditas, presentará, junto a Enric Mallorquí, en una próxima publicación. 
hubo de adaptarse Garcilaso a su llegada. Con este último objetivo, nos centraremos en los datos que nos proporcionan dos composiciones eglógicas nunca estudiadas ni editadas, que pertenecen a esos mismos papeles privados de los hermanos Seripando.

La cuestión que sorprende más cuando uno se adentra en el estudio y en la investigación de la poesía de Garcilaso es la falsedad del primer axioma que siempre se da por cierto cuando se empieza a hablar de su obra. El axioma que el propio Juan Boscán predicaba desde su carta a la duquesa de Soma: que gracias a su celebérrima conversación con Andrea Navagero en el Generalife, en 1526, había sido el primero en ensayarse en el endecasílabo, y por tanto, hay que deducir también de sus palabras, que fue él también el primer poeta que tuvo la iniciativa de imitar a los italianos. Lo repite varias veces a lo largo de la epístola, como si a base de reiterarlo resultara más convincente. No se puede negar que consiguió su propósito. Pero lo cierto es que cualquiera puede comprobar que esa afirmación es falsa. Todos intuíamos, algunos con más certeza que otros, que no era cierto, pero por respeto a lo que siempre se ha dicho, nadie se atrevía a explicitar esa duda. La argumentación que avala la hipótesis contraria, sin embargo, no es muy compleja. Es un simple problema cronológico y ya quedó explicado en otro lugar (Fosalba 2009). Navagero hubo por fuerza de intimar antes y mucho más con Garcilaso que con Boscán. El embajador de Venecia y Baldassare Castiglione compartieron con nuestro poeta largos meses en Toledo, en fechas anteriores a los sonados festejos de Granada de 1526; también es muy posible que siguieran tratándose en el inacabable periplo de los embajadores, hasta que Navagero pudo abandonar, a principios de 1528, Poza de la Sal, en Burgos, para volver a ver sus adorados jardines venecianos. Así, en esos largos meses - años, de hecho- pudo conocer Garcilaso no solo el tratado y la obra poética de Castiglione, sino también el contenido del diálogo de Fracastoro sobre poética a través del fecundísimo trato con Navagero, además de su obra poética, entre otros muchos textos que pudieron llegarle a las manos gracias a la conversación con ambos humanistas.

Estas breves consideraciones nos llevan a otro axioma que creo que ha frenado bastante los estudios garcilasistas, en cierta manera favorecido por el anterior (es decir, coadyuvado por la idea de que Garcilaso, en sus comienzos, iba a remolque de Boscán): la idea preconcebida, y que debe haber forzado en más de un caso la datación de sus poemas, de que Garcilaso empezó a recibir influencia italiana con motivo de sus viajes a Italia, sobre todo a raíz de los últimos años en Nápoles. Ya vamos viendo que no es rigurosamente cierto. Pero es que además hay algo que salta a la vista y desdice desde otro ángulo ese prejuicio. La integración de Garcilaso en Nápoles es vertiginosa y total en 1532. Es demasiado vertiginosa, sospechosamente veloz, a mi modo de ver. Podríamos aducir muchos detalles, pero solo mencionaré aquí unos pocos muy significativos (véanse más detalles en Fosalba: 2009, 2011, 2012): Cosme Anisio le dedica un epigrama neolatino escrito con algo de guasa, con mucho "compadreo" y con gran admiración y respeto, un epigrama 
que resulta que ya está publicado en $1533^{5}$. Mele asegura en nota que los epigramas de Cosme dedicados a Garcilaso estaban ya publicados en una edición de Sulzbach en 1531, un detalle que le indicó Croce; pero no he visto esa edición en ninguna biblioteca ni repertorio bibliográfico fiable y me pregunto si no será error de Mele, que a veces incurre en algún traspié tipográfico, en especial con las fechas (v. Mele 1898: 366). Si la edición existiera, sería prueba de la familiaridad mucho más temprana de Garcilaso con los círculos napolitanos; pero es muy dudosa, y es probable que no se trate más que de una confusión con la primera edición de los poemas de Giano Anisio, que sí es de 1531. Al editarse varios cuerpos de libros de los hermanos, unidos en una edición facticia, el auténtico colofón de Cosme quedó a continuación de la portada y edición más temprana de los textos de Giano. En cualquier caso, conviene resaltar aquí que el epigrama, que da por supuesta una amistad consolidada, aparece ya en papel de imprenta tan solo un año después de la llegada de Garcilaso a Nápoles.

De hecho, Garcilaso mismo explica esa integración velocísima en su oda neolatina dedicada al humanista cosentino Antonio Tilesio, una de cuyas copias se encuentra entre los papeles de Girolamo Seripando: se trata de una oda que ha desorientado a la crítica precisamente por esa razón a la hora de atribuirle una fecha, porque Garcilaso alude, como si se tratara de hechos recentísimos, a su confinación en la isla del Danubio, su abandono de la patria, de la esposa y de los hijos; sin embargo, en la tercera estrofa (y son estrofas alcaicas, de solo cuatro versos), es decir, en el verso noveno, Garcilaso se siente de nuevo consolado y feliz. De hecho, ya en la segunda estrofa había conseguido Antonio Tilesio quitarle las penas ${ }^{6}$. Fue Tilesio, nos cuenta Garcilaso, quien le presentó a alguien venerado por él como un padre (y Mele supone, creo que con acierto, que es Girolamo Seripando), la misma

${ }^{5}$ «Seu te Minerva vertit in lapidem dea / Sapientiae arduo obrigentem lumine, / Seu praeda Charitum ob nobilem speciem animi / Ac corporis, tibi nomen, istud incidit, / Vel quod Pelasgi sic pilosum nominant, / Catumque sicco corde, denso pectore, / Vel lassa nunquam beneficii est dandi domus /Tua: nomen operis aestimamus inclytum, / Charisyla amice Pieri sacris choris» (Anisio 1533: 91v.- 92r.). ( O bien la diosa Minerva te ha vuelto de piedra / que se endurece con la luz ardua de la sabiduría, / o bien el don de las Gracias te impuso este nombre / por el noble esplendor de tu mente y cuerpo, / o bien porque los griegos llaman así al peludo / y al hábil de corazón sencillo, de pecho denso, o bien sea que tu casa nunca se ha cansado del beneficio de dar:/ consideramos tu nombre famoso por tus servicios, / Charisyla, amigo de los sagrados coros de las Musas», traducción de Enric Mallorquí).

${ }^{6}$ Mele ofrece una breve biografía del humanista de Cosenza que resumo aquí: tío del filósofo Bernardino, nacido en 1482 y muerto en 1534 (habría que corregir por 1533, muy probablemente, como veremos en breve), fue profesor de latinidad y de retórica en Milán, donde conoció a Bandello, hacia 1517; en Roma, interpretó a Horacio; más tarde, en Venecia, fue lector y el 4 de mayo de 1529, obtuvo del Senado permiso para imprimir su tragedia Imber aureus. Acreditó su fama educando a su sobrino Bernardino, de quien solo se separó después del saqueo de Roma, volviendo él a Cosenza y enviando al sobrino a la Universidad de Padua. Desde Cosenza pasó a Nápoles, donde se encontraba en 1531 y donde trabó amistad con Scipione Capece y con el cardenal Pompeo Colonna (que murió el 28 de junio de 1532), de quien se prometía grandes cosas. Muerto Colonna y perdidas sus esperanzas, retornó a su ciudad natal, Cosenza, en la Calabria, donde murió (Mele 1923: 138). 
mano que le condujo al grupo de humanistas y poetas en el que se siente como pez en el agua. Fue en la ciudad partenopea donde recuperó la inspiración. Y el adverbio temporal iam, reiterado anafóricamente, denuncia la rapidez de esa transformación de su ánimo.

\author{
Uxore, natis, fratribus et solo \\ exsul relictis, frigida per loca \\ Musarum alumnus barbarorum \\ ferre superbiam et insolentes \\ mores coactus, iam didici invia \\ per saxa, voces ingeminantia \\ fletusque, sub rauco querelas \\ murmure Danubii levare. \\ O nate tristem sollicitudine \\ lenire mentem et rebus atrociter \\ urgentibus fulcire amici \\ pectora docte manu, Thylesi! \\ Iam iam sonantem Delius admovet \\ dexter tacentem barbiton antea; \\ cantare Sebethi suädent \\ ad vaga flumina cursitantes
}

Nymphae; iam amatis moenibus inclitae non urbis, amnis quam Tagus aureo nodare nexu gesti, ultra me lacerat modum amor furentem.

Sirenum amoena iam patria iuvat cultoque pulchra Parthenope solo iuxtaque manes consedere vel potius cineres Maronis. ${ }^{7}$

${ }^{7}$ Cito por la edición de Alcina y Villalonga en la edición de la obra de Garcilaso a cargo de Morros (Garcilaso ed. 1995: 251-254). La traducción de Alcina reza así: «Tras abandonar exiliado a mi esposa, mis hijos, hermanos y tierras, por frías regiones, alumno de las Musas, aprendí a soportar forzado la soberbia y las fieras costumbres de los bárbaros, y por peñascos intransitables que repetían mis voces y gemidos, a la orilla del ronco murmullo del Danubio, aprendí a sobrellevar mis penas. ¡Oh docto Tilesio! Nacido para apaciguar el pensamiento entristecido por las cuitas y reconfortar con tu mano el pecho del amigo en los momentos terriblemente urgentes. Ya el diestro Apolo acerca la sonora lira a quien antes callaba; las ninfas del Sebeto que corretean por los sinuosos ríos incitan al canto. Ya no me oprime desmedidamente el amor ardiente por los amados muros de la ínclita ciudad que el río Tajo gusta anudar con su dorado abrazo. Ya me agrada la vida en la amena patria de las sirenas y la hermosa Parténope con sus campos cultivados, y asentarme junto a los manes o mejor las cenizas de Marón». 
Por otro lado, en la misma oda también se menciona a Mario Galeota y Placido di Sangro, como si de grandes amigos se tratara ${ }^{8}$. Se ha aducido que Garcilaso no podía haber consolidado tantas amistades en tan poquísimo tiempo y que, por tanto, la oda debe de ser de hacia 1534, que es la fecha en que se suele suponer que Antonio Tilesio murió. Pero, por el contrario, la oda parece más bien testimonio de esa integración instantánea a que antes aludíamos; una suerte de adaptación facilísima que solo se daría si Garcilaso ya fuera un poeta plenamente formado en las últimas tendencias de la poesía italiana cuando llegó a Nápoles a la altura de 1532. Además, Tilesio murió en 1533, según figura en la Vita de Francesco Daniele de 1762, biografía que a su vez se refiere a la epístola de Pandosius dirigida a Pietro Antonio Sanseverino, donde se daba la noticia del óbito, en un texto que vio la luz en Roma en 1534 (fecha esta motivo más que probable de la confusión general con el año de la muerte del humanista cosentino $)^{9}$. O sea, que Garcilaso hubo de escribir la Oda a Tilesio, todo lo más, tan solo un año después de su llegada a Nápoles. Se refuerza así, desde este otro ángulo, la certeza de que Garcilaso se consoló rápido de su nostalgia por la patria y que en cuestión de pocos meses había hallado un grupo de humanistas y poetas que le trataban como a un amigo entrañable y compartían con él todas sus inquietudes intelectuales y artísticas.

¿Qué otros datos relacionables con la estancia e intereses literarios de Garcilaso en Nápoles podemos entresacar de la Oda a Tilesio? Para empezar, la oda está dedicada a él no solo por gratitud, sino también por otras posibles razones más literarias, como la común admiración por Horacio -inclinación por el venusino, dicho sea de paso, compartida por Girolamo Seripando y Placido di Sangro (v. n. 10)-, a cuya defensa y alabanza dedicó Tilesio un opúsculo en donde concibe su obra como culminación de la lírica clásica. Es este interés un punto en común con Garcilaso nada desdeñable, teniendo en cuenta que el toledano vuelve los ojos a Horacio - una vez más- en la articulación formal de la oda que dedica a su amigo; Horacio era con toda probabilidad el poeta clásico al que Tilesio tenía, en efecto, en la más alta estima, pues en su apología llegaba a equipararlo a Virgilio. A su vez, la anotación de Tilesio aparece recogida junto a la de otros comentaristas y escoliastas (Acrón, Por-

\footnotetext{
${ }^{8}$ Mele se complacía en referir un pasaje de una carta de Girolamo Seripando a Placido di Sangro pasaje que ya había dado a conocer Fiorentino- que ponía de manifiesto que la amistad que se estrechó entre él y el poeta español derivaba de la común inclinación en ambos hacia los poetas latinos. Acerca del modo de traducir escribía el prelado agustino: «No quiero decir más, recordando haber escrito también, hace años, cuando practicaba este estudio, a aquel honorabilísimo y virtuosísimo caballero Garcilaso de la Vega, nuestro común amigo, requerido por él (que, como sabéis era estudiosísimo de Horacio, y lo imitaba en sus escritos felizmente), como yo entendía este pasaje» (Mele 1923: 135).

${ }^{9}$ "Ac mors ex transverso incurrens in tumulum urget: circa annum namque 1533 [Joh. Antonius Pandosius (De coena Domini, Romae, 1534) in epistola dedicatoria ad Petrum Antonium Sanseverinum, data Kal. Juniis eiusdem ani 1534...] in patria decessit» (Daniele 1762: vii).
} 
firio, Parrasio, Poliziano, Sabellico, Crinito, Ricchieri, Manunzio, Pio, etc.), en una edición ascensiana de la opera omnia del venusino ${ }^{10}$.

Garcilaso alude de forma bastante explícita en sus versos al Imber aureus (lluvia de oro) de Tilesio, tragedia sobre el mito de Danae, que se considera uno de los mejores dramas mitológicos de su tiempo, publicado en 1529, en Venecia: una tragedia de fuerte impronta lírica, en la que el elemento mitológico se introduce sin pedantería y con admirable naturalidad ${ }^{11}$. Este dato nos recuerda, por otro lado, que Antonio Tilesio fue gran amigo de Coriolano Martirano, autor a su vez de tragedias neolatinas, quien le dirigió varias epístolas; puede que fuera este, hermano de Bernardino Martirano, tan apegado este último al Emperador (discípulo de Aulo Giano Parrasio, oriundo, como su hermano Coriolano y el propio Tilesio, de Cosenza), el punto de contacto entre Garcilaso y el círculo de Girolamo Seripando.

La oda podría iluminar, además, el lugar de reunión de la tertulia (o tertulias) postpontaniana, frecuentada por Garcilaso, y continuadora de la extinta academia de Villa Mergellina. No estoy del todo segura acerca de que el acomodo para las reuniones fuera exacta y exclusivamente en la villa de Scipione Capece, como se suele suponer; hay otras posibles ubicaciones de esa academia (Fosalba 2009, 2011). Se ha discutido acerca de la posible fecha del nacimiento de Capece; sobre si había nacido hacia 1508, dado el contenido de la elegía IV que el jurisconsulto escribió en 1538, donde parecía afirmar que tenía 31 años; pero es una interpretación poco plausible $^{12}$. Lo que está claro es que Capece se casó en 1526 , con lo cual lo más probable es que hubiera nacido a fines del $\mathrm{XV}$, y que debía tener, por tanto, más o menos, la edad del propio Garcilaso: es poco probable así que Garcilaso lo adorara como a un padre, como se afirma en la Oda a Tilesio de esa autoridad reverenciada, de la que no se facilita el nombre, y que aglutina a los humanistas y poetas del entorno de Tilesio y el mismo Garcilaso («sese parentis quem veneror loco») $)^{13}$. Las preocupaciones teológicas de esa autoridad aludidas en la oda a Tilesio podrían también ser las de Seripando y, en cualquier caso, lo que parece claro es que Garcilaso se refiere a la mansión honorable (honesta domus) del mismo personaje que tiene a todos absortos con sus especulaciones. Parece más probable que siga refiriéndose a Girolamo y el círculo de poetas que quedan recogidos en los manuscritos de los hermanos Seripando; el mismo círculo que había en su entorno en casa de

${ }^{10}$ El encomio Antonii Thylesii Consentini in Odas Horatii Fracci auspicia ad ivventutem romanam se puede leer en opúsculo aparte, sin fecha ni impresor. Puede consultarse la edición de Q. Horatii Flacii... Omnia poemata, de Venecia, apud J. Gryphium, 1584.

${ }^{11}$ También tiene un acento personal el poema acerca de la figura polifémica, en donde se humaniza al monstruoso jayán, y se compadece su ceguera, que ya no le permitirá ver más a Galatea. Hay edición bastante reciente de Jan-Wilhelm Beck con traducción e introducción al alemán (Tilesio ed. 2000).

${ }^{12}$ Antonio Altamura (1941: 156) se corrigió a sí mismo al reconocer que Scipione Capece debió nacer a finales del XV si se casó en 1526, como atestigua, precisamente, el Epithalamium in nuptias Scipionis Capycii et Juniae [sic] Caracciolae, Neapoli, apud Evangelistam Papiensem, 1526 (Altamura1959: 299-300).

${ }^{13}$ En cambio, Girolamo Seripando nació en 1493. 
Girolamo. Así lo contaba Giano Anisio en una de sus sátiras publicadas en 1532, en la que se explayaba describiendo lo acogedoras que eran las veladas en la morada de Girolamo ${ }^{14}$. Pero más plausible es que el lugar de reunión fuera alguna estancia o los jardines del mismo San Giovanni a Carbonara, convento agustino a las puertas de Nápoles, dirigido por Girolamo durante catorce años (1523-1538) como vicario general, en donde, además, se custodiaba su biblioteca, que había pasado a engrosarse con la parrasiana: todos esos impresos y códices anotados por el gran humanista de Cosenza que los hermanos Seripando heredaron sucesivamente de él (primero Antonio; y tras su óbito, en 1531, Girolamo) $)^{15}$. Una tertulia poética a la que se acercaba Capece, saliendo del foro, como atestigua años antes Girolamo Carbone (m. 1528) en unos versos dedicados a Nipho, donde el magistrado aparece en compañía de otros humanistas postpontanianos, como Anisio, Seripando, Parrasio, además de Summontius, Apranius y Sangrius, unidos todos por la amistad ( $\lll \mathrm{O}$ fidum sanctae pectus amicitiae!») $)^{16}$. Pero además queremos dar cuenta de un detalle curioso; también Carbone menciona la extraordinaria capacidad oratoria de Seripando, cuyo efecto compara a temibles truenos; ¿quién no teme -pregunta- cuando él truena y los cielos se afligen por el dolor de la voluntad divina? Sin embargo, lleno de piedad, y reverenciado en vida, cultiva estos lares con sagrada religión.

Quos inter nostras demulcet ANISIUS aures,

Pindaricos uaria dum canit arte modos.

Inuisit cultus SIRIPANDUS sedulus hortos,

Ingenii repetens tot monimenta sui,

Doctaque PARRHASII scripta et memoranda per aeuum,

O fidum sanctae pectus amicitiae!

Quem non alterius SIRIPANDI fulmina terrent,

Cum tonat et caeli numina laesa dolent?

Ille tamen, pietate grauis, uitaque uerendus,

Excolit hos sancta relligione lares ${ }^{17}$.

${ }^{14}$ Ad Hieronyum Seripandum: «Quum me tu officiose Hieronyme adisti, ego summo / Mane domo externam accitus conviva, pedesque / Martini monte superavi, qui imminet urbi / plurimus et molem et subiectas despicit arces / Quae quondam Ponti spoliis fulsere rebellis. / Ianutius Zandeus festiuissimus inter / Mortales, Decius, Carafa, Sebastus Ethruscus, / Et Borellus, sunt me umbrae tum forte secuti. / Sectatur Sargus vel per maria omnia mullum / Vix erecta in collem acies, pulmonis anheli / nec dum etiam pressi folles, animaque residunt». (Satyrae 1532: 28v.-29v.).

${ }^{15}$ Acerca del más que posible acceso de Garcilaso a la biblioteca parrasiana, v. Fosalba (2011).

${ }^{16}$ También se menciona a los dedicatarios de dos églogas latinas que se encuentran entre los papeles de los Seripando y que reseñaremos sucintamente un poco más adelante; ellos son, el conde de Travanillo (Cavanilus) y Acquaviva (Dux Aquauiue).

${ }^{17}$ Este pasaje de los versos dedicados a Nipho pueden leerse en la edición de De Montera (1935: 52-53). De Montera entiende que aquí se alude a Antonio Seripando, que durante muchos años fue secretario del Cardenal Ludovico de Aragón. Pero en principio, las dotes oratorias eran a todas luces las de su hermano Girolamo. 
«Reverenciado en vida» («uitaque uerendus») recuerda las palabras de Garcilaso al referirse a quien veneraba como a un padre, «sese parentis quem veneror loco»:

\section{Te, mi Thylesi, te comite obtulit sese parentis quem veneror loco, cui dulce pignus nostri amoris non animum pigeat patere}

Y no podemos olvidar aquí, por supuesto, que la última carta de Garcilaso, dirigida a Seripando, donde vuelca sin miedo sus aprensiones, es testimonio diáfano de que es a él a quien abre su corazón; ese ser «a quien no le avergüenza abrir su alma como dulce prenda de su amor» (en traducción de Juan Alcina). La faceta afectiva es muy importante en Garcilaso, y en este sentido, los testimonios aducidos parecen corroborar que Seripando le gana el pulso a Capece ${ }^{18}$.

Lo interesante de la oda de Garcilaso es que en ella es el mismo poeta quien nos explica que el círculo que lo acogió es precisamente el de Girolamo Seripando. Y donde debió ensayarse en la poesía neolatina, aunque no es probable que acometiera el tema sacro, que parece interesó a buena parte de los miembros de la tertulia de San Giovanni, sobre todo a Capece ${ }^{19}$, en buena medida a Sannazaro, y también a Coriolano Martirano. Más datos de esa tertulia pueden arañarse del diálogo Cicero relegatus \& Cicero revocatus, dialogi festivissimi, publicado en Milán, en 1534, en parodia del ciceronianismo y anticiceronianismo acerbos, donde Ortensio Lando, su autor, recuerda sus tiempos en el convento de San Giovanni a Carbonara y aporta, como ejemplo de ciceronianos, si bien no estrechos de miras, a los frailes con quienes convivió en calidad de fray Hiremias: aparecen también Girolamo Seripando y su hermano Antonio. No olvidemos que cuando Lando estuvo en Nápoles, Antonio todavía vivía, pues su estancia tuvo lugar antes de 1531; después de esa fecha Lando se marchó a Milán, donde reubica su diálogo, para actualizarlo en 1534. Muy significativamente, en el diálogo de Ortensio Lando, comparecen formando parte del grupo napolitano del entorno de los Seripando, como también sucedía en la oda a Tilesio y en parte en la Ode ad florem Gnidi de Garcilaso, los dos amigos del toledano: Placido di Sangro y Mario Galeota. Placido di Sangro fue amicísimo de Antonio y después de

${ }^{18}$ De todas formas, esta última afirmación está sujeta a revisión.

${ }^{19}$ Scipione Capece tiene el De nativitate Domini y el De vate maximo, donde se analiza la figura de San Juan Bautista, desde su primera educación a su vida campestre, desde el bautismo de Cristo hasta la historia de Herodías y la degollación. Altamura explica que está inspirado en la musa épica de Virgilio pero que está construido todo sin el aparato de imágenes mitológicas de las que los predecesores de Capece habían echado mano en sus poemas. Discípulo de Summonte, hijo del jurisconsulto Antonio Capece, ocupó el cargo de gobernador de Scipione, ocupó la cátedra de derecho civil en sustitución de Gaspare de Leo en 1534, y a partir de 1539 fue consejero del monasterio de Santa Chiara en Nápoles. 
Girolamo. Los papeles de los hermanos Seripando contienen asimismo numerosas cartas a ambos de parte de Placido di Sangro ${ }^{20}$.

Parece que Antonio fue poeta a su vez, como avala que se conserven composiciones con la anotación al margen, «manu et opera Antonii Seripandi». Aunque Fuiano duda de la validez de esta anotación, lo cierto es que Parrasio llama a Antonio, «alumno de las musas» («alumnusque Musarum», véase n. 21). Antonio, mayor que Girolamo, fue quien con toda probabilidad, con su amor por la filología, su generosidad de ánimo y su hondo sentido de la amistad, hizo posible el grupo. Hay un claro paréntesis de Parrasio en este sentido en su prolusión a sus anotaciones a las epístolas de Cicerón a Ático, cuando explica lo que supusieron para él los consejos de Antonio a la muerte de Leon X, que había sido como un hermano y un padre para él, pues le protegía cuando, incluso en su alta presencia, los envidiosos se atrevían a criticarle. Todo lo habría abandonado al morir el pontífice si no hubiera sido por Antonio Seripando, nacido en la más alta alcurnia de Nápoles y tan exquisitamente sabio; relata Parrasio entonces como Antonio, tomando ejemplos de la historia, trató de consolar su dolor, poniéndole como parangón, sin ir más lejos, al cardenal Luis de Aragón, a quien tantos años había servido el mismo Antonio como secretario, quien en la muerte de su padre Alfonso y en la más dura adversidad, supo mantener la serenidad ${ }^{21}$. Estos datos dibujan así la figura de Antonio Seripan-

${ }^{20}$ Junto a composiciones de Antonio Seripando (por confirmar), Decio Apranio, Lepiro, Pomponio Gaurico, Giovanni Andrea, Cino da Pistoia, Vincentus Galeota, Hieronimus Carbo, P. Feltri, Marco Antonio Casanova, Salvio Capelletti, Crispoldo Crispoldi, Seraphinus Griphonus Reatinus, entre otros. Otras composiciones aparecen dedicadas a Antonio y Girolamo Seripando, Parrasio (quizá de Girolamo Seripando; es conjetura de Kristeller 1998: 549), Jacobus Sadoleto, Angelus Ubaldus, Francescus Lombardus.

${ }^{21}$ «Quum vix a ferula subducta manu, praeter assiduas auctorum Graecorum, solertesque expositiones, Annibalis, Romanorumque res in Hispania, ac Italia gestas, ab Appiano secretis operibus illustratas, Latii jure nondum donatas, adeo luculenter, atque sententiarum fide, verborumque splendore transtulit, ut undecunque doctissimum Leonem X. Admiratio legentem subierit. Et audet aliquis in tanta propinqui jactura, qui me diligebat, ut fratrem, colebat, ut patrem, lacrymis modum praescribere? Et est, qui sucenseat nihil a nobis allatum festivi, quod animos exhilaret, quod aures impleat, quod expectationi respondeat? Quanto verius illud onjiceretur, quod post ictum tanti fulminis haec infelicissima mihi, meisque studia retentarim, nec oderim, nec damnarim, nec abjecerim? Quod equidem jam fecissem, nisi intercessisset Antonius Seripandus in illa doctissima nostra Neapoli summo loco natus, alumnusque Musarum, de nobis optime meritus: is, ut est disertissimus, exemplis ab historia repetitis agere mecum coepit, ut dolori resisterem: quumque rogando parum proficeret, afflictumque frustra tentaret erigere, alia adortus est via, auremque vellit hunc in modum: cogitarem, quis hominum de me sermo post illa contra Fortunam magnifica verba turpiter abjecto futurus esset, quod amplissimi patris, \& utriusque nostrum communis herois Aragonei Lysiae judicium, qui, tot amissis antea regibus, \& nuper Alphonso patrueli, quem sa-crosanctus Gallorum rex in avitam, paternamque dignitatem reducturus erat, eundem vultum frontemque servavit: quam Leo decimus in partem sit accepturus hanc animi mollitiem paene muliebrem, qui censor omnium maximus in suis aequabilitatem desiderat, quam ipse praestat in omni vita: qui nec adversis unquam fractus, nec secundis elatus esse traditur. Illud etiam monuit, ne malevolis ansam darem, qui sinistris me sermonibus apud ipsum quoque Pon- 
do, siempre en prudente segundo plano, receptivo, cálido, cuidadoso compilador de obras y misivas del grupo: el retrato del verdadero secretario in pectore, durante largos años, de los círculos potspontanianos de la Nápoles aragonesa. De hecho, Fuiano se sorprendía de que Antonio fuera capaz de sostener una tierna amistad con el propio Sannazaro, quien le dedica varias cartas, conservadas entre esta misma documentación, en algunas de las cuales le pide consejo estilístico sobre el De partu Virginis $^{22}$, como a su vez había solicitado a Iacopo Sadoleto y Antonio Tebaldeo.

Girolamo, no menos generoso que Antonio, a quien sobrevivió largos años, con fortísima personalidad intelectual, y con un profundo sentido de la amistad a su vez, continuaría la labor galvanizadora de su hermano. Es curioso que en la oda a Tilesio haya una deuda con las Silvas de Estacio, que es uno de los primordiales caballos de batalla del gran polígrafo Parrasio. Aunque Parrasio hubiera muerto diez años antes, sigue siendo posible así su influencia en el toledano, a través de su obra, fielmente custodiada en el convento agustino de Nápoles. Por otra parte, Giovanni Pontano nos recuerda la costumbre adquirida bajo la tutela de Egidio de Viterbo de dialogar paseando por los jardines de S. Giovanni a Carbonara, en compañía de otros humanistas como el propio Pontano, Benedetto Cariteo o Girolamo Carbone, y parece lo más probable que se reprodujera años más tarde, teniendo como centro, entonces, a Girolamo Seripando.

Muchos de los poemas consignados en los papeles de los hermanos Seripando, copiados algunos de la mano de Antonio, son, por lo que parece, de una generación anterior a Garcilaso, buena parte de ellos al menos diez años anteriores (otros contemporáneos, bien es cierto $)^{23}$, y se han conservado gracias a la curiosidad filológica y hondo sentido de la amistad de Antonio, y después de Girolamo. De entre ellos se hallan dos églogas, que nos proponemos editar en otro lugar, como botón de muestra de la colección: la primera dedicada a Carlos $\mathrm{V}^{24}$ y al príncipe Traiano Cabanillo, conde de Tria y de Montella, y la segunda al duque de Acquaviva; ambas ponen de manifiesto la estrecha relación entre los hermanos Seripando - que conservaron los textos-y las instancias más altas del poder imperial, que son objeto del panegírico: Antonio, discípulo del florentino Francesco Pucci, sirvió muchos años como fidelísimo secretario a Luis de Aragón en Roma; Girolamo vivió una carrera imparable hacia las más altas esferas esclesiásticas: de secretario de Egidio Viterbo, pasó a Vicario general de la orden en 1538, obispo de Aquila (1551), arzobispo de Salerno (1554) y cardenal (1561), además de participar muy activamente en el concilio de Trento. De

tificem carpere non erubescerent. Denique turpe esse in id aetatis, \& professionis homine remedium doloris lassitudinem moerendi. Quibus gravissimi viri vocibus expugnatus in potestate me tandem fore promisi, intermissamque Ciceronis interpretationem resumpturum.» (Parrasio 1771: 250-252).

${ }^{22}$ Béhar ha citado un fragmento de una de esas cartas (del 13 de abril de 1521) en un documentado artículo sobre la influencia del De partu Virginis en Garcilaso (2009: 65).

${ }^{23}$ Contemporáneo a la estancia de Garcilaso en Nápoles es el epigrama latino dedicado a la muerte de Ariosto (m. 1533), por ejemplo (Ms. XIII AA 63, f. 65). Sería interesante investigar su autoría.

${ }^{24}$ «Microtii Amatricis ad eximios Sem. Mediol. Juuenes. Ecloga» (Ms. XIII AA63, f. 93r.) y «Pastores Mosticus, Egenus et Alphesiboeus» (Ms. XIII AA 63, f. 54). 
Girolamo es una oración fúnebre por la muerte del Emperador, sello de esta clara vinculación, muy representativa a su vez de la doble vertiente del contacto que estableció el propio Garcilaso con los poetas y humanistas napolitanos. Las sátiras de Giano Anisio resultan reveladoras al respecto: las hay dedicadas a los dos hermanos Seripando (la de Antonio, escrita entre 1522 y 1523, en vida de Adriano IV), además de a Girolamo Borgia, Iacopo Sannazaro, Lepiro, Pomponio Gaurico, Antonio Tilesio $\mathrm{y}$, por supuesto, a los hermanos Coriolano y Bernardino Martirano. Este último es a su vez representativo del punto de contacto entre los grupos de humanistas postpontanianos y los círculos del poder. Bernardino Martirano los recibía como es sabido en Leucopetra: Bernardino fue, además, discípulo de Parrasio y estuvo al lado del Condestable de Borbón en el saqueo de Roma, lo que le valió numerosas prebendas por parte del Emperador; para empezar el cargo de Secretario de Estado del Virrey Pedro de Toledo desde 1532 hasta 1548. En gratitud, Bernardino Martirano dedicó versos en alabanza del Emperador en su poema de largo aliento Aretusa.

Las dos églogas neolatinas inéditas a que aludíamos pertenecen al grupo de manuscritos de la Biblioteca Nacional de Nápoles donde se conservan la carta de Garcilaso y sus dos poemas neolatinos, el dedicado a Tilesio y el dedicado a Venus. Ambas églogas neolatinas se encomiendan a los círculos del poder, en circunstancias que arrojan una fecha anterior a la estancia garcilasiana, como ya anunciábamos. La primera égloga es obra de Microtius Amatricius y está dirigida a los distinguidos miembros del seminario de Milán, en lo que no es más que un canto pastoril en que Coridón pide a Mopsus le cuente sobre la felicidad de los pastores que se reclinan ahora en las aguas del río milanés Ticinus, con gran contento, gracias a la prosperidad que ha traído la gran gloria de Carlos, hay que suponer tras la victoria de Pavía. En respuesta, y con extrema humildad, Mopsus desea y profetiza que muy pronto también los pastores del Tíber aceptarán el gobierno del mismo Carlos ${ }^{25}$.

La segunda égloga está a su vez dedicada en el cuerpo del texto a dos personajes de la más alta alcurnia en la Nápoles anterior a la llegada de Garcilaso: el Príncipe Traiano Cabanillo, a quien Sannazaro había dedicado una de sus piscatorias, noble a su vez de origen español, que al quedar huérfano de padre -fallecido en la batalla de Otranto- pasó a ser protegido del Duque de Calabria, Alfonso. El rey Ferrante se preocupó de que recibiera una esmerada educación humanista, así que muy pronto entró a formar parte de la élite intelectual pontaniana, como poeta diletante. De hecho, fue a su vez un grandísimo mecenas que acogió en su palacio a una corte formada por la flor y nata de los académicos napolitanos, no solo literatos sino también filósofos y científicos. Iacopo Sannazaro y Giano Anisio se hospedaron en sus dominios y gozaron de su protección. Anisio le dedica un larguísimo poema halagüeño que abre su libro de Sátiras (publicado en 1532, pero elaborado muchos años antes; el príncipe ya había muerto, en 1528, en la misma fecha en que perdió la vida el otro militar, el duque de Acquaviva, a quien también se dirige la bucólica). El

${ }^{25}$ Como ya mencioné, Enric Mallorquí, experto latinista, ofrecerá próximamente edición y traducción de dichas églogas, precedidas de un estudio introductorio nuestro. 
género de la égloga, haciendo honor a su emblemática servidumbre (quien a buen árbol se arrima, buena sombra le cobija), pone a su vez de manifiesto en estos dos ejemplos de pastoral neolatina las superposiciones irrenunciables de jerarquías y humanismo en la Nápoles aragonesa.

Garcilaso llegó más tarde a estos círculos de nobles y literatos dedicados a las Musas en que ambas composiciones eglógicas florecieron; algunos poetas y nobles ya habían muerto, pero las estructuras pervivían y nuestro poeta participó doblemente en ellas: como poeta principalísimo entre los italianos, y como noble estrechamente vinculado a las más altas esferas del poder en la Nápoles imperial: los poetas y humanistas italianos le veían como parte del establishment; eso explica que fuera posible mecenas del humilde Tansillo (quien así se refiere a nuestro poeta en uno de sus sonetos encomiásticos), favor pretendido a través de la alabanza de la obra latina del toledano de parte del gran Pietro Bembo para favorecer a Honorato Fascitel. Eso no quiere decir que este encomio interesado esté reñido con el verdadero aprecio por el poeta innovador, admirado por sus sinceros amigos. Pero Garcilaso aterrizó en esas viejas estructuras jerárquicas para formar parte de ellas, conviene no olvidarlo.

Las aguas auríferas del Tajo que Garcilaso recuerda en su oda a Tilesio (y en su égloga III, así como en su soneto a María Cardona), signo de identidad que dejaba atrás, adquirieron bajo su pluma un nuevo sentido nostálgico, desautomatizador del topos clásico, adecuado al sentir de la más alta nobleza española que adoptó Nápoles como nueva patria. De hecho, el dorado abrazo de la ciudad imperial ya se había actualizado en la piscatoria de Iacopo Sannazaro dirigida a Fernando de Aragón, hijo del rey Federico, de origen español, retenido en esos momentos en España por Carlos V. Sannazaro le invitaba así a abandonar ese paisaje que formaba parte de sus raíces, para volver a los parajes napolitanos de adopción. No extraña así que para dar a entender su feliz integración en Nápoles cifrara Garcilaso el terruño en la mítica imagen de las doradas arenas que habían quedado definitivamente atrás, en un viaje irreversible hacia la inspiración, tras las náyades del Sebeto (cantare Sebethi suadent / ad vaga flumina cursinantes / nimphae...); un viaje acuático que, como el de Aretusa, conectaría la vieja con la nueva patria.

\section{BIBLIOGRAFÍA}

Altamura, Antonio (1941): L'umanesimo nel mezzogiorno d'Italia: storia, bibliografie e testi inediti, Napoli, Bibliopolis.

AltamurA, Antonio (1959): «Per la biografia di Scipione Capece», en Studi in onore di Riccardo Filangieri, Napoli, L'arte tipografica, II, pp. 299-315.

ANISIO, Giano (1532): Iani Anysii saturae ad Pompeium Columnam Cardinalem, [colofón:] Neapoli ex officina Ioannis sulsbacchi Hagenovensis germani.

ANISIO, Cosme (1533): Cosmi Anysii poemata, Neapoli per Ioannem Sutzbacchium Hagenovesem Germanum. 
BÉHAR, Roland (2009): «Virgilio, san Agustín y el problema del poema heroico cristiano (1520-1530)», Criticón 107, pp. 57-92.

Bellsolell, Joan (2010): «Miquel Mai y Antonio Sebastiano Minturno en la corte de Carlos V», Studia Aurea. Revista de Literatura Española y Teoría Literaria del Renacimiento y Siglo de Oro 5, pp. 139-178. <http://www.studiaaurea.com/ articulo.php?id=159\&idi $=$ ESP $>$

DE MONTERA, Pierre (1935): L'humaniste napolitain Girolamo Carbone et ses poesies inedites, Napoli, Pubblicazioni della scuola di perfezionamiento in lingue e letterature moderne nella R. Università di Napoli.

FosALBA, Eugenia (2009): «Implicaciones teóricas del alegorismo autobiográfico en la égloga III de Garcilaso», Studia Aurea. Revista de Literatura Española y Teoría Literaria del Renacimiento y Siglo de Oro 3, pp. 39-104.

FosAlBA, Eugenia (2011): «El exordio de la Epístola a Boscán: contexto napolitano», Studia Aurea. Revista de Literatura Española y Teoría Literaria del Renacimiento y Siglo de Oro 5, 23-47.

FosAlBA, Eugenia (2012): «A vueltas con el descuido de Garcilaso y Boscán», en E. Fosalba y G. Pontón (eds.), La escondida senda. Estudios en homenaje a Alberto Blecua, Barcelona, Castalia, pp. 147-164.

FUIANO, Michele (1969): Insegnamento e cultura a Napoli nel Rinascimento, Napoli, Libreria Scientifica Editrice.

GALLO, Italo (1998): v. GAURICO.

GAURICO, Pomponio (ed. 1998): Inno greco a Fabrizio Brancia, ed. de I. Gallo, Napoli, Arte tipografico.

KRISTELLER, Paul Oskar (1998 [1977]): Iter italicum. A finding list of uncatalogued or incompletely catalogued humanistic manuscripts of the Renaissance in Italian and other libraries. Vol. II Italy, Orvieto to Volterra, Vatican City, Londres, The Warburg Institute.

MARTIRANO, Bernardino (1993): Il pianto d'Aretusa, a cura di Tobia Toscano, Napoli, Loffredo.

Mele, Eugenio (1898): «Una oda latina inédita de Garcilaso de la Vega y tres poesías inéditas a él dedicadas por Cosimo Anisio», Revista de Crítica de Historia y Literatura españolas, portuguesas e hispanoamericanas 3, pp. 362-368.

Mele, Eugenio (1923): «Las poesías latinas de Garcilaso de la Vega y su permanencia en Italia», Bulletin Hispanique 25, pp. 108-148.

PARRASIO, Aulo Giano (1771): Auli Jani Parrhasii Consentini quaesita per epistolam ex recensione Henr. Stephani; in Neapolitana hac editione acceserunt quaedam ex Parrhasii $m$. ss. excerpta cum auctoris vita conscripta ab Xaverio Matthaei, Typographis Simoniis fratribus, Napoli.

VEGA, Garcilaso de la (ed. 1995): Obra poética y textos en prosa, ed. de B. Morros, Barcelona, Crítica.

TILESIO, Antonio (1792): Antonii Thilesii consentini opera, excud. Fratres Simonii, Napoli.

TILESIO, Antonio (ed. 2000): Antoni Thylesii Consentini Imber aureus, mit einer Einleitung zu den antiken Voraussetzung der Tragödie, ed. de Jan-Wilhelm Beck, Bern, Peter Lang (Biblotheca Humanistica 7). 